\title{
Parametric Study of MSW Landfill Settlement Model
}

\author{
G. L. Sivakumar Babu, Professor \\ Department of Civil Engineering, Indian Institute of Science, Bangalore 560012, India \\ e-mail: gls@civil.iisc.ernet.in
}

Krishna R. Reddy, Professor

Department of Civil and Materials Engineering, University of Illinois at Chicago, 842 West Taylor Street, Chicago, Illinois 60607, USA e-mail: kreddy@uic.edu

Sandeep K. Chouksey, Research Scholar

Department of Civil Engineering, Indian Institute of Science, Bangalore 560012, India e-mail: sandeepkc@civil.iisc.ernet.in

August 162010 


\title{
Parametric Study of MSW Landfill Settlement Model
}

\author{
G. L. Sivakumar Babu; Krishna R. Reddy; and Sandeep K. Chouksey
}

\begin{abstract}
A newly developed and validated constitutive model that accounts for primary compression and time-dependent mechanical creep and biodegradation is used for parametric study to investigate the effects of model parameters on the predicted settlement of municipal solid waste (MSW) with time. The model enables the prediction of stress strain response and yield surfaces for three components of settlement: primary compression, mechanical creep, and biodegradation. The MSW parameters investigated include compression index, coefficient of earth pressure at-rest, overconsolidation ratio, and biodegradation parameters of MSW. A comparison of the predicted settlements for typical MSW landfill conditions showed significant differences in timesettlement response depending on the selected model input parameters. The effect of lift thickness of MSW on predicted settlement is also investigated. Overall, the study shows that the variation in the model parameters can lead to significantly different results; therefore, the model parameter values should be carefully selected to predict landfill settlements accurately. It is shown that the proposed model captures the time settlement response which is in general agreement with the results obtained from the other two reported models having similar features.
\end{abstract}

Key Words: MSW, landfill, settlement, constitutive model, biodegradation, creep 


\section{Introduction}

Prediction of municipal solid waste (MSW) landfill settlement is required to assess the integrity of cover systems and appurtenant systems (gas and leachate collection pipes), estimate the landfill airspace, and design the end-use facilities (e.g., golf course, industrial/commercial building). MSW settlement is mainly attributed to: (1) physical and mechanical processes that include the reorientation of particles, movement of the fine materials into larger voids, and collapse of void spaces; (2) chemical processes that include corrosion, combustion and oxidation; (3) dissolution processes that consist of dissolving soluble substances by percolating liquids and then forming leachate; and (4) biological decomposition of organics with time depending on humidity and the amount of organics present in the waste.

Several models have been reported in the literature to predict settlement of landfills (Park and Lee, 1997, Machado et al. 2002, Marques et al. 2003, Machado et al. 2008). For example, Park and Lee (1997) proposed a settlement model that considers time-dependent biodegradation of waste. The settlement rate is assumed to be the amount of subsidence that is directly proportional to the amount of solids solubilized. Solubilization of organic materials is generally expressed using first-order kinetics. Marques et al. (2003) presented a model to obtain the compression of MSW in terms of primary compression in response to applied load, secondary mechanical creep, and time-dependent biological decomposition. The model performance was assessed using data from the Bandeirantes Landfill, which is a well-documented landfill located in Sao Paulo, Brazil, in which an instrumented test fill was constructed. It was found that the composite model tracked observed patterns of landfill settlement very well. It was observed that a single set of parameter values can provide reasonably good representation of all the waste in the vicinity of the test fill and recommendations for applying the model to other landfills are 
provided. Machado et al. (2008) presented a constitutive model for MSW based on elastoplasticity considering that the MSW contains two component groups; the paste and the fibers. The effect of biodegradation is included in the model using a first order decay model to simulate gas generation process through a mass balance approach while the degradation of fibers is related to the decrease of fiber properties with time. The predictions of stress strain response from the model and observations from the experiments were compared and guidelines for the use of the model are suggested.

Reddy and his co-workers (Reddy et al. 2009a,b, c) presented considerable data on the geotechnical characteristics of MSW in landfills in different degrees of biodegradation which are useful for evaluation of models. In the recent years, to understand the stability and deformation response of landfill structures, analysis using numerical tools such as finite elements and finite differences to understand the stress-deformation behavior of MSW has become necessary. These models are based on elasto-plasticity concepts and models to predict stress-strain response of MSW considering all processes contributing to the total settlement are required. Babu et al. (2010a) proposed a generalized MSW landfill settlement model which accounts for the stressstrain characteristics through a constitutive model based on critical state concepts. The advantage of this model is that it is based on the stress-strain (constitutive) response of MSW and it is a general model which can be applied to determine spatial variations in settlement depending on the landfill conditions. The model accounts for primary compression and time-dependent mechanical creep and biodegradation. The model is validated using the data of Reddy et al. (2009a, b and c) from (a) fresh MSW obtained from working phase of a landfill, (b) landfilled waste retrieved from a landfill after a year of degradation, and (c) synthetic MSW with controlled composition. The model captures the stress-strain and pore water pressure response of 
these three types of MSW adequately. Babu et al. (2010b) illustrated the applicability of the model for a typical MSW landfill. The predicted settlement results were compared with the predicted settlement results obtained using fourteen different reported models. It is shown that the predicted settlements can vary significantly depending on the model used and the parameter values selected. Two of these reported models were developed by Marques and his collaborators (Marques, 2001; Marques et al., 2003) which account for mechanical compression, mechanical creep and biodegradation similar to the constitutive model developed by Babu et al. (2010). Marques (2001) model considers the mechanical compression based on consolidation theory and the mechanical creep and biodegradation through exponential decay functions. Marques et al. (2003) further developed the model and termed it composite compressibility model by considering the waste placement by a series of lifts. All these models require comprehensive geotechnical testing and analysis as well as evaluation of geotechnical parameters for computation of time-settlement response.

This paper first provides an overview of the models of Marques (2001) and Marques et al. (2003) and the constitutive model of Babu et al. (2010a) and then highlights the need for parametric studies. Next, it investigates the general applicability of these models based on a systematic parametric study considering variations of different parameters for typical landfill conditions. Finally, the implications emerged from the parametric study are highlighted.

\section{Settlement predictive models}

The total strain is given by:

$$
\varepsilon=\varepsilon_{P}+\varepsilon_{C}+\varepsilon_{B}
$$


The three terms, $\varepsilon_{P}, \varepsilon_{C}$ and $\varepsilon_{B}$ represent strains resulting from response to applied load, timedependent strain due to mechanical creep, and time-dependent strain due to biological decomposition, respectively.

Composite Rheological Model (Marques, 2001)

Marques (2001) developed a composite rheological model to account for the primary and secondary compression and biodegradation mechanisms represented by

$$
\frac{\Delta H}{H}=C_{C}^{\prime} \log \left(\frac{\sigma_{0}+\Delta \sigma}{\sigma_{0}}\right)+\Delta \sigma b\left(1-e^{-c t^{\prime}}\right)+E_{d g}\left(1-e^{-d t^{\prime \prime}}\right)
$$

where $\Delta H=$ settlement; $H=$ initial height of waste; $C_{C}^{\prime}=$ primary compression ratio; $\sigma_{0}=$ existing overburden pressure acting at midlevel of the layer; $\Delta \sigma=$ increment of overburden pressure acting at midlevel of the layer from the construction of an additional layer; $b=$ coefficient of secondary mechanical compression; $c=$ secondary mechanical compression rate; $E_{d g}=$ total compression due waste degradation; $d=$ secondary biological compression rate; $t^{\prime}=$ time elapsed since loading application; and $t^{\prime \prime}=$ time elapsed since waste disposal; layer;

Modified Composite Rheological Model (Marques et al., 2003)

Marques et al. (2003) further developed the model and termed it modified composite compressibility model that incorporates three mechanisms for one-dimensional compression of MSW viz. instantaneous response to load, mechanical creep, and biological decomposition and also includes lift wise loading of MSW. In implementing the composite model, waste placement is idealized as progressing in a series of lifts, as schematically illustrated in Fig. 1. The thickness 
of the lifts may be set equal to the compacted thickness of the daily cells. After all lifts have been placed, the settlement $\Delta \mathrm{H}$, of the landfill surface at time, $\mathrm{t}$, is determined.

The total settlement is given by:

$\Delta \mathrm{H}=\sum_{i=1}^{N} H_{i}\left[\varepsilon_{P i}+\varepsilon_{C i}(t)+\varepsilon_{B i}(t)\right]$

where $N=$ number of lifts in the landfill; $H_{i}=$ initial thickness of compacted lift $i ; \varepsilon_{P i}=$ strain in lift $i$ resulting from instantaneous response to loading from overlying lifts; $\varepsilon_{C i}=$ strain at time $t$ in lift $i$ due to mechanical creep associated with the stresses from the self-weight and the weight of overlying lifts; and $\varepsilon_{B i}=$ strain at time $t$ in lift $i$ due to biological decomposition of lift $i$. The strains are given by:

$\varepsilon_{P i}=C_{c}^{\prime} \log \left(\frac{\frac{1}{2} \gamma_{i} \Delta \mathrm{H}_{i}+\sum_{j=i+1}^{N} \Delta \sigma_{i j}}{\frac{1}{2} \gamma_{i} \Delta \mathrm{H}_{i}}\right)$

$\varepsilon_{C i}(t)=b\left[\frac{1}{2} \gamma_{i} \Delta \mathrm{H}_{j}\left(1-e^{-c\left(t-t_{i}\right)}\right)+t_{j} \sum_{j=i+1}^{N} \Delta \sigma_{i j}\left(1-e^{-c\left(t-t_{j}\right)}\right)\right]$

$\varepsilon_{B i}(t)=E_{d g}\left(1-e^{-d\left(t-t_{i}\right)}\right)$

where $\gamma_{i}$ is unit weight of lift $i ; \Delta \sigma_{i j}=$ increment of vertical stresses imposed by lift $j$ on lift $i$ for $j>i$; and $t_{i}$ and $t_{j}=$ times at which lifts $i$ and $j$, respectively, were placed. The value of 
$\gamma_{i}$ composite value representing the weighted average of the compacted waste and daily cover in lift $i$. Because $t$ is a time after lifts of the landfill have been placed, $t-t_{i}>0$ and $t-t_{j}>0$ for values of $i$ and $j$. If lift $j$ is of great lateral extent compared to depth of lift $i$, the value of $\Delta \sigma_{i j}$ is equal to the product of $\mathrm{H}_{j}$ and $\gamma_{i}$. Depending on the amount of information available for a particular landfill under consideration, the parameter values were adjusted to provide the best fit with the available data. This model has been validated with reference to field measurements.

\section{Babu et al. (2010) Model}

Babu et al. (2010a) proposed a constitutive model which can be used to determine settlement of MSW landfills based on constitutive modeling approach. In this model, the elastic and plastic behavior as well as mechanical creep and biological decomposition are used to calculate the total volumetric strain of the MSW under loading as follows:

$d \varepsilon_{v}=d \varepsilon_{v}^{e}+d \varepsilon_{v}^{p}+d \varepsilon_{v}^{c}+d \varepsilon_{v}^{b}$

where $d \varepsilon_{v}^{e}, d \varepsilon_{v}^{p}, d \varepsilon_{v}^{c}$ and $d \varepsilon_{v}^{b}$ are the increments of volumetric strain due elastic, plastic, time dependent mechanical creep and biodegradation effects, respectively. The elastic volumetric strain $d \varepsilon_{v}^{e}$ can be written as:

$d \varepsilon_{v}^{e}=-\frac{d e^{e}}{1+e}=\frac{\kappa}{1+e} \frac{d p^{\prime}}{p^{\prime}}$

And, increment in plastic volumetric strain can be written as

$$
d \varepsilon_{v}^{p}=\left(\frac{\lambda-\kappa}{1+e}\right)\left[\frac{d p^{\prime}}{p^{\prime}}+\frac{2 \eta d \eta}{M^{2}+\eta^{2}}\right]
$$

The above formulations for increments in volumetric strain due to elastic and plastic are well established in critical state soil mechanics literature (Wood, 1990). 
The mechanical creep is a time dependent phenomenon in exponential function given by

$\varepsilon_{v}^{c}=b \Delta p^{\prime}\left(1-e^{-c t^{\prime}}\right)$

where $b$ is the coefficient of mechanical creep; $\Delta p^{\prime}$ is the change in mean effective stress, $c$ is the rate constant for mechanical creep; and $t^{\prime}$ is the time since application of the stress increment. The biological degradation is a function of time and is related to the total amount of strain that can occur due to biological decomposition and the rate of degradation. The time dependent biodegradation is given by

$\varepsilon_{v}^{b}=E_{d g}\left(1-e^{-d t^{\prime \prime}}\right)$

where $E_{d g}$ is the total amount of strain that can occur due to biological decomposition; $d$ is the rate constant for biological decomposition; and $t^{\prime \prime}$ is the time since placement of the waste in the landfill.

From Eq. (8), increment in volumetric strain due to creep is written as:

$d \varepsilon_{v}^{c}=c b \Delta p^{\prime} e^{-c t^{\prime}} d t^{\prime}$

From Eq. (9), increment in volumetric strain due to biodegradation effect is written as:

$d \varepsilon_{v}^{b}=E_{d g} e^{-d t^{\prime \prime}} d t^{\prime \prime}$

In the present case $t^{\prime}$ time since application of the stress increment and $t^{\prime \prime}$ time since placement of the waste in the landfill are considered equal to ' $t$ '.

Using Eqs. (6), (7), (10), and (11) and substituting in Eq. (1), total increment in strain is given by

$d \varepsilon_{v}=\frac{\kappa}{1+e} \frac{d p^{\prime}}{p^{\prime}}+\left(\frac{\lambda-\kappa}{1+e}\right)\left[\frac{d p^{\prime}}{p^{\prime}}+\frac{2 \eta d \eta}{M^{2}+\eta^{2}}\right]+c b \Delta \sigma^{\prime} e^{-c t} d t+E_{d g} e^{-d t} d t$ 


\section{Calculation of settlement response for MSW using constitutive model (Babu et al., 2010a)}

A typical MSW landfill of $30 \mathrm{~m}$ height has been considered which is assumed to be filled in the ten layers each of $3 \mathrm{~m}$ deep as shown in Fig. 2. At the top of landfill, a final cover system has been assumed to be constructed which consists of composite liner (compacted clay and geomembrane) overlain by a sand drainage layer and then a vegetative cover soil layer. This typical landfill situation is considered for estimation of time-settlement response using the models of Marques (2001), Marques et al (2003) and Babu et al (2010a). In order to predict the settlement response of MSW under loading conditions under different lifts for different layers (from bottom to top), the following initial parameters are used for the each layer: water content, specific gravity, coefficient of earth pressure at-rest $\left(\mathrm{K}_{\mathrm{o}}\right)$, compression index and recompression index. The procedure for calculating settlement response for different layers is as follows: For example, let us consider P1 layer. Referring to Fig. 2,

1. Calculate the initial void ratio $\mathrm{e}_{1}$ from the basic parameters.

2. The MSW is considered as normally consolidated and $\mathrm{OCR}=1, K_{o}^{n c}$ can be directly used from measurements or calculated using suitable expressions available in literature.

3. Initially, when there is no fill and hence vertical and horizontal stresses are given by $\sigma_{z 1}^{\prime}=\gamma H$ and $\sigma_{x 1}^{\prime}=\sigma_{z 1}^{\prime} * K_{0}^{n c}$.

4. The stresses on the initial yield surface are given by

$$
\left(p_{c}^{\prime}\right)_{1}=\frac{1+2 K_{o}^{n c}}{3} \sigma_{z 1}^{\prime} \&\left(q_{c}^{\prime}\right)_{1}=\left(1-K_{o}^{n c}\right) \sigma_{z 1}^{\prime}, \quad \sigma_{z 1}^{\prime}=\gamma H
$$

5. The stress at the centre of 1 st layer is expressed as

$$
\sigma_{v}^{\prime}=\frac{(P 10)}{2} * \gamma \text { and } \sigma_{h}^{\prime}=\sigma_{v}^{\prime} * K_{0}^{n c}
$$

6. Stress increase is given by 
$\Delta p_{1}^{\prime}=\frac{\sigma_{v}^{\prime}+2 \sigma_{h}^{\prime}}{3}$ and $\Delta q=\left(\sigma_{v}^{\prime}-\sigma_{h}^{\prime}\right)$

7. The mean effective stress is expressed as:

$p_{1}^{\prime}=\left(p_{c}^{\prime}\right)_{1}+\Delta p^{\prime}$

8. In the model, the pre-consolidation pressure is a time dependent function. It depends upon creep and biodegradation. The details are given in Babu et al. (2010a). From model, the pre-consolidation pressure is expressed as:

$$
p_{0}^{\prime}=\left[\left(\frac{\Delta q}{M p_{1}^{\prime}}\right)^{2}+1\right]^{\frac{\lambda-\kappa}{\lambda}} \frac{\Delta p_{1}^{\prime}}{\exp \left\{\left[\frac{\left(e_{0}-e\right)}{1+e_{0}}+b \Delta \sigma e^{-c t}+E_{d g} e^{-d t}\right](1+e)\right\}}
$$

It may be noted that the above equation also enables the calculation of pre-consolidation pressure if there is time lag by using appropriate modifications in the second term in the exponential of the denominator.

9. From the above calculated pre-consolidation pressure $\left(p_{0}^{\prime}\right)$, settlement response of $\mathrm{P} 1$ is expressed as:

$$
\Delta s=\frac{H}{1+e_{1}} \lambda \ln \left[\frac{p_{a}^{\prime}}{p_{1}^{\prime}}\right]
$$

10. Similar calculations are performed for other layers. The loading due to nine additional lifts induces further settlements in the first layer. The effect of the additional incremental loading is obtained using steps 6 and 7. Additional settlement due to fill load is obtained as follows.

11. Considering fill load, the overburden pressure at the centre of 1st layer is expressed as

$$
\sigma_{v}=\delta P+\frac{(P 1)}{2} * \gamma \text { and } \sigma_{h}=\sigma_{v} * K_{0}^{n c}
$$


12. This settlement can be calculated based on equations in steps 8 and 9 .

13. Total settlement for the P1 can be obtained summing all the values of settlement.

The landfilling is assumed to occur in a series of lifts of certain thickness $\left(\mathrm{H}_{\mathrm{i}}\right)$ and the settlement in each thickness at a time is calculated assuming one-dimensional compression conditions $\left(d \varepsilon_{v}=d \varepsilon_{H i}\right)$. Subsequently, the settlements in all the layers are added to obtain the total settlement in the landfill.

\section{Evaluation of different components of MSW settlement using different models}

The quantification of various components of overall MSW settlement is of primary interest in the analysis of the long-term compressibility analysis of landfills. Table 1 presents the components of settlements in terms of (i) settlement due to primary compression only, (ii) settlement due to primary compression and mechanical creep (iii) settlement due to primary compression and biodegradation effect and (iv) settlement due to primary compression, mechanical creep and biodegradation effect computed using the proposed model. It can be noted that the primary compression constitutes $63.7 \%$, creep contributes to additional $8.2 \%$ and the biodegradation contributes to $28.1 \%$ for the ultimate settlement based on the model of Marques (2001). Model of Marques et al. (2003) gives settlement components in which primary compression constitutes $63.2 \%$, creep contributes to additional $9.6 \%$ and the biodegradation contributes to $27.2 \%$. The proposed model gives contributions to the ultimate settlement in the range of $60 \%$ for primary compression, $20.9 \%$ for creep and $19.1 \%$ for biodegradation. Hence, though the values of ultimate settlement are in the same range, the contributions of each component are marginally different. The proposed model gives higher creep settlements due to 
mechanical creep and lower values for settlement due to biodegradation for the set of data considered. Thus the observed values of settlement are in the similar range and comparable to the predicted values from the model of Marques et al. (2003) which has been validated with reference to field studies. Further, the proposed model has the advantage of obtaining stress strain response of the MSW due to the three mechanisms separately as well as collectively as shown in Fig. 3 for the set of parameters presented in Table 2. Fig. 3 shows the stress strain response due to three components separately as well as collectively. It is also possible to obtain yield surfaces for different times that correspond to total settlement as shown in Fig. 4. These two aspects are unique features of the proposed model presented herein.

\section{Need for parametric study}

The settlement predictive models involve many parameters related to compressibility and biodegradation which vary widely. For example, Machado et al. (2008) showed that biodegradation is modeled in terms of strength and stiffness of fibers that are biodegradable. Literature review indicates that the influence of the parameters related to (i) compressibility $\left(C_{c}\right)$, (ii) coefficient of earth pressure at-rest $\left(\mathrm{K}_{\mathrm{o}}\right)$ (iii) overconsolidation ratio (OCR) (iv) total

biodegradable strain $\left(E_{d g}\right)$, and (v) biodegradation rate constant $(d)$ on the settlement response is significant.

Compressibility of waste is important from the integrity viewpoint of the landfill structure. Waste compresses due to increase in effective stress (primary compressibility) and due to mass loss from biodegradation (secondary compressibility). The compressibility of waste was first studied by Sowers (1973) and he reported that the compression index (Cc) is related to the initial void ratio $\left(\mathrm{e}_{\mathrm{o}}\right)$ and can vary between $0.15 \mathrm{e}_{\mathrm{o}}$ to $0.55 \mathrm{e}_{\mathrm{o}}$. The upper limit corresponds to MSW containing large quantities of food waste and high decomposable materials. The value of 
secondary compression index $\left(\mathrm{C}_{\alpha}\right)$ varied between $0.03 \mathrm{e}_{\mathrm{o}}$ to $0.09 \mathrm{e}_{\mathrm{o}}$. Results of Gabr and Valero (1995) showed consolidation tests that yielded $\mathrm{Cc}$ varying from 0.4 to 0.9 , and $\mathrm{C}_{\alpha}$ varying from 0.03 to 0.009 for the initial void ratios $\left(\mathrm{e}_{\mathrm{o}}\right)$ in the range of approximately 1.0 to 3.0. Machado et al. (2002) obtained the values of primary compression index which varied between 0.52 and 0.92. It is lower for lower MSW void ratios, which confirms the interdependence of $C_{c}$ and $e$.

With increased use of bioreactor landfills which involves leachate recirculation to enhance biodegradation in contrast to traditional dry landfills, there is a need to study the effect of biodegradation on time-settlement response. Bareither et al. (2010) showed that the rate of time-dependent waste settlement attributed to biodegradation is about 1.6 times larger in bioreactor landfills than in conventional landfills, and increases as the recirculation dosage increases. The time dependent strain due to biodegradation is expressed by equation which uses $E_{d g}$, the parameter related to total amount of strain that can occur due to biodegradation and $d$ is the rate constant for biological decomposition. This approach was proposed by Park and Lee (1997) to correlate biological degradation and the associated secondary settlements with the solubilization rate of degradable matter in solid waste. The total biodegradable strain $E_{d g}$ depends on the total biodegradable material present which can vary from very low values (less than $1 \%$ ) to values as high as $25 \%$. For example, Marques et al. (2003) reported the values of total biodegradable strain varying from 0.214 to 0.131 with an average value of 0.159 . Barlaz et al. (2010) analyzed the performance of different types of landfills in terms of chemical and biological characteristics and showed that bioreactor landfills supported accelerated methane generation at several landfills. The gas generation was in the range of $0.08-0.211 /$ year relative to the default decay rate of $0.041 /$ year. The rate constant in the biological decomposition is 
expressed by the rate of biodegradation $(d)$ and Marques et al. (2003) reported an average value of 0.0114 day $^{-1}$ for this parameter.

It may be stated that while the qualitative influence of these parameters on settlement of MSW is known, it is essential to obtain the values in quantitative terms in terms of timesettlement behavior for different parameters and this is possible by conducting parametric studies using suitable models discussed earlier and consider all the above factors.

\section{Parametric study}

The objective of this study is to examine the results of variation of landfill settlement with time for a typical layer (for example, P6 layer) considering the variations of different ranges of parameters over 30 years (10,950 days, which is typically the landfill closure time specified) and draw inferences with regard to time-settlement response of MSW.

\section{Influence of compression index $\left(C_{c}\right)$}

Using the proposed model, for different values of compression index from 0.30 to 0.60 , time-settlement response is predicted keeping the other parameters constant. Fig. 5 shows the

settlement response for the different values of compression index. Comparison of values of maximum settlement from all the three models and the model parameters used are given in Table 3. Figs. 6(a)-(d) show the comparison of time-settlement response for the different models for various values of compression index. It can be noted that the higher values of compression index are associated with larger settlements.

It can also be noted that there is a good agreement between the predictions of the constitutive model and those from the models proposed by Marques (2001) and Marques et al. 
(2003). There are minor differences in the settlement at the initial stage, but the ultimate settlement at the end of 30 years (10950 days) is very close. This observation lends support to the use of newly developed constitutive model as well as the models of Marques and co-workers in the prediction of settlement of MSW. The general observation from all three models is that with increasing values of compression index, the predicted value of ultimate settlement is more.

\section{Influence of earth pressure at-rest $\left(K_{o}\right)$}

Earth pressure coefficient $\left(\mathrm{K}_{\mathrm{o}}\right)$ is one of the important parameters which influences the engineering response of MSW. Several researchers presented various ranges of values of coefficient of earth pressure at-rest in a highly scattered form. For example, Dixon et al. (1999) estimated in-situ $\mathrm{K}_{\mathrm{o}}$ values for 1 to 3 years old MSW and 11 years old MSW using a self-boring pressure meter. The $\mathrm{K}_{\mathrm{o}}$ values in this case are estimated by moderate strains induced by the

pressure meter test and gave typical ranges of $\mathrm{K}_{\mathrm{o}}$ from 0.16 to 0.85 . Landva et al. (2000) conducted a series of large-scale one-dimensional compression tests with measurements of lateral stresses and estimated $\mathrm{K}_{\mathrm{o}}$ for five reconstituted specimens of MSW, with fiber different compositions. $\mathrm{K}_{\mathrm{o}}$ values reported for the five specimens were $0.4,0.35,0.33,0.34,0.26$, with the results suggesting that the $\mathrm{K}_{\mathrm{o}}$ value reduces from 0.4 to 0.23 as the fiber content increases.

In the present study, different values of earth pressure at-rest $\left(\mathrm{K}_{\mathrm{o}}\right)$ have been used in the calculation of MSW settlement using the proposed model, while keeping the all other parameters the same. Fig. 7 shows the variation of settlement with earth pressure at-rest $\left(\mathrm{K}_{\mathrm{o}}\right)$. It should be noted that MSW is assumed normally consolidated in calculating the settlement; in other words overconsolidation ratio (OCR) has been taken equal to one. From Fig. 7, it is seen that for $\mathrm{K}_{\mathrm{o}}=$ 0.10 , the computed settlement reached to $17.38 \mathrm{~m}$, while for $\mathrm{K}_{\mathrm{o}}=0.90$, the settlement is $7.50 \mathrm{~m}$. 
From these results, it is concluded that the with increase in earth pressure at-rest $\left(\mathrm{K}_{\mathrm{o}}\right)$ settlement is reduced.

\section{Influence of overconsolidation ratio (OCR)}

Generally, it is assumed that the MSW is normally consolidated with $\mathrm{OCR}=1$. In order to investigate the effects of increased OCR, settlement was computed assuming different values of OCR ranging from 1.0 to 2.0. Fig.8 shows the variation of settlement with respect to different values of OCR. From Fig. 8 it is observed that the settlement decreases with increase in OCR. The results indicate that for $\mathrm{OCR}=1$, the ultimate settlement was estimated as $7.93 \mathrm{~m}$, whereas for OCR $=1.8$ the ultimate settlement was decreased to $7.15 \mathrm{~m}$.

\section{Influence of total biodegradation strain $\left(E_{d g}\right)$}

Coduto and Huitric (1990) stated that settlement caused by biodegradation of landfill wastes may constitute about $18-24 \%$ of the total MSW thickness. Al-Khafaji and Andersland (1981) mentioned that the settlement of organic soils due to decomposition of organics might in some cases be more significant than settlement induced by applied loadings. With increased use of bioreactor landfills which involve leachate recirculation to enhance biodegradation in contrast to traditional dry landfills, there is a need to study the effect of biodegradation on time-settlement response. To model biodegradation, in the proposed model, it is assumed that at time $t=0$, there is no biodegradation strain and as time increases the biodegradation strain increases reaching a final value corresponding to the total biodegradation strain. The total biodegradation strain can be related to the total biodegradable matter present in the MSW. In the model of Machado et al. (2008), it is assumed that the biodegradation process is represented by the strength and stiffness 
of the fibers, reflected in yielding deviator stress and initial Young's modulus of fibers, which decrease with time.

To assess the settlement behavior of MSW with respect to biodegradation effect using the proposed model, four different values of total biodegradable strain, $E_{d g}(0.07,0.12,0.15$ and 0.18) are used, while keeping the biodegradation rate constant (d) the same. Marques et al. (2003) reported the values of $E_{d g}$ varying from 0.214 to 0.131 with an average value of 0.159 .

Comparison of time-settlement response for different values of total biodegradable strain $\left(E_{d g}\right)$ is shown in Figs. 9(a)-(d). The maximum settlements observed from different models corresponding to different values of $E_{d g}$ and additional constant parameters are presented in Table 4. The results predicted from the constitutive model show similar variations in timesettlement response as those of the two other models. From the plotted results, it is observed that the model predictions of settlements are highly influenced by the values of total biodegradable strain. The predicted results show that biodegradation effect is more pronounced causing higher settlements in the case of waste materials having higher values of biodegradable content. Thus, the degree of settlement depends on the quantity of biodegradable waste present in MSW.

\section{Influence of rate of biodegradation $(d)$}

The rate of strain due to biological decomposition is expressed by the rate of biodegradation $(d)$ in Eq. (5). Marques et al. (2003) reported an average value of 0.00114 day $^{-1}$ Barlaz et al. (2010) reported values of rate constant in the range of 0.04 to 0.17 year $^{-1}$ or 0.00011 to 0.00046 day $^{-1}$. Based on this, different values of this parameter are selected for this study: $0.00011,0.00022,0.00032$ and 0.00041 day $^{-1}$. The time-settlement response is calculated for 
these different values of total strain rate $(d)$, while keeping the other parameters the same. Comparison of the settlement response from the different models is shown in Figs. 10(a)-(d). The results show that the rate of degradation affects settlement. For smaller values of rate constant, the maximum settlement observed from all models is almost very close. For higher values of biodegradation rate constant, higher settlement resulted, hence enhancement of biodegradation rates, using such methods as leachate recirculation, helps in accelerated settlement. The maximum settlements observed from different models corresponding to different values of $d$ are also summarized in in Table 5.

\section{Influence of waste lift thickness}

The waste lift thickness is an important aspect in landfilling operations. Hence, the effect of different lift thicknesses is studied by varying it from $0.5 \mathrm{~m}$ to $3 \mathrm{~m}$. The results are presented in Fig. 10, and it can be noted that the lift thickness has significant influence on the settlement pattern from initial stage to ultimate settlement. For example, the ultimate settlement value in 30 years (10950 days) varied from 2.80 to $8.90 \mathrm{~m}$ as the lift thickness is changed from $0.5 \mathrm{~m}$ to 3.0 $\mathrm{m}$, whereas initial settlement (after one day) varied from 2.30 to $6.90 \mathrm{~m}$. This shows that the waste lift thickness should be given proper consideration in numerical modeling studies for accurate prediction of settlement. The ultimate settlement of landfill depends on the waste lift thickness used while filling operations.

\section{Conclusions}

This study presents a parametric study on the influence of compressibility, earth pressure at-rest $\left(\mathrm{K}_{\mathrm{o}}\right)$, overconsolidation ratio $(\mathrm{OCR})$ and biodegradation parameters on the predicted time- 
settlement response of MSW based on the proposed constitutive model. The compressibility parameter plays a significant role in the time compression response. For example, MSW with low compressibility undergo less settlement with time which can be captured adequately by the model. As expected, the total biodegradation strain and the rate of biodegradation significantly influence the settlement response. This aspect can be advantageously used in the design of bioreactor landfills involving leachate recirculation to accelerate biodegradation and settlement. The predicted results from the constitutive model (Babu et al., 2010a) are compared with the predictions obtained from the models of Marques (2001) and Marques et al. (2003) and the results show that the predicted values are in the same range. The proposed constitutive model also accounts for overconsolidation ratio and earth pressure at-rest. It is observed that the higher values of overconsolidation ratio and earth pressure at-rest result in lower settlement. The study shows that choice of waste lift thickness in modeling also has significant influence on settlement of MSW. The advantage of the constitutive model of Babu et al. (2010a) is that it is a general model based on the stress-strain behavior of MSW and it can be used in for detailed deformation analysis of landfills.

\section{Acknowledgements}

The authors thank the reviewers for critical and constructive comments toward the preparation of this paper. This project is a collaborative effort between the Indian Institute of Science Bangalore and the University of Illinois at Chicago. Partial funding is provided by the U.S. National Science Foundation (Grant CMMI \#0600441), which is gratefully acknowledged. 


\section{References}

Babu Sivakumar, G. L., Reddy, K.R., Chouskey, S.K. 2010a. Constitutive model for municipal solid waste incorporating mechanical creep and biodegradation-induced compression. Waste Management Journal, 30(1), 11-22.

Babu Sivakumar, G. L., Reddy, K.R., Chouskey, S.K., Kulkarni, H. 2010b. Prediction of longterm municipal solid waste landfill settlement using constitutive model. Practice Periodical of Hazardous, Toxic, and Radioactive Waste Management, ASCE, 14(2), 139150.

Barlaz ,M. A., Bareither., C. A., Hossain, A., Saquing, J., Mezzari, I., Benson, C. H., Tolaymat, T. M., Yazdani, R. 2010. Performance of North American bioreactor landfills. II: Chemical and biological characteristics. Journal of Environmental Engineering, ASCE, . 136(8), 839-853.

Bareither, C. A.; Benson, C.H., Barlaz; M.A., Edil, T.B., Tolaymat, T.M. 2010. Performance of North American bioreactor landfills. I: Leachate hydrology and waste settlement, Journal of Environmental Engineering, 136(8), 824-838.

Dixon, N., Jones, D. R. V., Whittle, R. W. 1999. Mechanical properties of household waste: In situ assessment using pressuremeters, Proceedings Sardinia 99, Seventh International Waste Management and Landfill Symposium.

Gabr, M.A., Valero, S.N., 1995. Geotechnical properties of solid waste. ASTM, Geotechnical Testing Journal 18 (2), 241-251.

Kavazanjian, E. Jr., and Matasovic, N. 1995. Seismic analysis of solid waste landfills. Proc., Geoenvironment 1995. ASCE Geotechnical Special Publication 46, 1066-1080 
Landva, A. O., Valsangkar, A. J., Pelkey, S. G. 2000. Lateral earth pressure at rest and compressibility of municipal solid waste, Canadian Geotechnical Journal, 37, pp. 11571165.

Landva, A.O., Clark, J.I. 1986. Geotechnical testing of waste fill. Proc., $39^{\text {th }}$ Canadian Geotechnical Conference, Ottawa, Ontario, 371-385.

Machado, S. L., Vilar, O. M., Carvalho, M. F. 2008. Constitutive model for long - term municipal solid waste mechanical behavior." Computers and Geotechnics., 35, 775 - 790.

Machado, S.L., Carvalho, M.F., Vilar, O.M. 2002. Constitutive model for municipal solid waste. Journal of Geotechnical and Geoenvironmental Engineering, ASCE, 128(11), 942-951.

Manassero, M., Van Impe, W. F., Bouazza, A. 1996. Waste disposal and containment. Proc., $2^{\text {nd }}$ Int. Congr. on Environmental Geotechnics, Osaka, Japan, Balkema, Rotterdam, The Netherlands 3,1425-1474.

Marques, A. C. M., Filz, G. M., Vilar, O. M. 2003. Composite compressibility model for municipal solid waste. J. Geotech. Geoenviron. Eng., 129(4), 372-378.

Marques, A.C.M. 2001. Compaction and compressibility of municipal solid waste Ph.D Thesis, Sao Paulo University, Sao Carlos, Brazil.

Park, H. I., Lee, S. R. 1997. Long-term settlement behavior of landfills with refuse decomposition. J. Resour. Manage. Technol., 24(4), 159-165.

Reddy, K.R., Hettiarachchi, H., Gangathulasi. J., Bogner, J.E., Lagier, T., 2009c. Geotechnical properties of synthetic municipal solid waste. International Journal of Geotechnical Engineering, 3(3), 429-438. 
Reddy, K.R., Hettiarachchi, H., Parakalla, N., Gangathulasi. J., Bogner, J.E., Lagier, T., 2009b. Geotechnical properties of landfilled municipal solid waste under short-term leachate recirculation operations. Waste Management \& Research, 27(6), 578-587.

Reddy, K.R., Hettiarachchi, H., Parakalla, N.S., Gangathulasi. J., Bogner, J.E., 2009a. Geotechnical properties of fresh municipal solid waste at Orchard Hills Landfill, USA. Waste Management, 29(2), 952-959.

Sowers, G.F., 1973. Settlement of waste disposal fills. In: Proceedings of the 8th International Conference on Soil Mechanics and Foundation Engineering, Moscow, USSR 2.2, 207210.

Van Impe, W.F. 1998. Environmental geotechnics: ITC5 activities - state of the art. Proc., 3rd Int. Cong. on Environmental Geotechnics, Lisbon, Portugal, 4, 1163-1187. 


\section{Tables}

Table 1 Comparison of ultimate settlements using different models considering primary compression, mechanical creep and biodegradation

\begin{tabular}{lcccc}
\hline \multicolumn{1}{c}{ Model } & $\begin{array}{c}\text { Primary } \\
\text { compression } \\
(\mathrm{m})\end{array}$ & $\begin{array}{c}\text { Primary } \\
\text { compression } \\
\text { creep }(\mathrm{m})\end{array}$ & $\begin{array}{c}\text { Primary compression } \\
\text { + Biodegradation }(\mathrm{m})\end{array}$ & $\begin{array}{c}\text { Total } \\
\text { settlement }(\mathrm{m})\end{array}$ \\
\hline Marques (2001) & 5.42 & 6.12 & 7.80 & 8.51 \\
Marques et al. & 5.61 & 6.46 & 8.04 & 8.88 \\
$(2001)$ & 5.09 & 6.86 & 8.36 & 8.47 \\
Proposed model & & & & \\
\hline
\end{tabular}

Table 2. Parameter values used to obtain stress-strain response of MSW

\begin{tabular}{ll}
\hline Parameter & Values \\
\hline Compression index, $\lambda$ & 0.1734 \\
Swelling index, $\kappa$ & 0.0043 \\
Initial void ratio $e_{0}$ & 0.4268 \\
friction angle, $\phi^{\prime}$ & 20 \\
Over-consolidation ratio, OCR & 1 \\
Specific gravity, G & 0.97 \\
Rate constant for mechanical creep, c & $0.001790 \mathrm{day}^{-1}$ \\
Coefficient of mechanical creep, b & $0.000572 \mathrm{~m}^{2} / \mathrm{kN}$ \\
Total amount of strain due to biological decomposition, $E_{d g}$ & 0.150 \\
Rate constant for biological decomposition, d & $0.001140 \mathrm{day}^{-1}$ \\
\hline
\end{tabular}

Table 3. Effect of compression index on maximum MSW settlement (m) using different models

$$
\left(\phi=20^{\circ}, E_{d g}=0.150, \mathrm{~d}=0.00011 \mathrm{day}^{-1}\left(0.04 \mathrm{year}^{-1}\right)\right)
$$

\begin{tabular}{cccc}
\hline $\begin{array}{c}\text { Compression } \\
\text { index }\left(C_{c}\right)\end{array}$ & $\begin{array}{c}\text { Marques } \\
(2001)\end{array}$ & Marques et al. (2003) & $\begin{array}{c}\text { Proposed constitutive } \\
\text { model }\end{array}$ \\
\hline 0.30 & 6.36 & 6.28 & 6.10 \\
0.40 & 7.72 & 8.23 & 8.18 \\
0.50 & 9.02 & 9.63 & 9.67 \\
0.60 & 10.2 & 11.0 & 11.5 \\
\hline
\end{tabular}


Table 4. Effect of total biodegradation strain on maximum MSW settlement $(\mathrm{m})$ using different models $\left(\phi=20^{\circ}, \mathrm{Cc}=0.40, \mathrm{~d}=0.00011 \mathrm{day}^{-1}\left(0.04\right.\right.$ year $\left.\left.^{-1}\right)\right)$

\begin{tabular}{cccc}
\hline $\begin{array}{c}\text { Total biodegradation } \\
\text { strain }\left(E_{d g}\right)\end{array}$ & Marques (2001) & Marques et al. (2003) & $\begin{array}{c}\text { Proposed constitutive } \\
\text { model }\end{array}$ \\
\hline 0.070 & 6.82 & 7.24 & 7.49 \\
0.120 & 7.32 & 7.79 & 7.86 \\
0.150 & 7.63 & 8.13 & 8.17 \\
0.180 & 8.13 & 8.69 & 8.74 \\
\hline
\end{tabular}

Table 5. Effect of rate of biodegradation (d) on maximum MSW settlement (m) using different models $\left(\phi=20^{\circ}, E_{d g}=0.150, \mathrm{Cc}=0.40\right)$

\begin{tabular}{cccc}
\hline $\begin{array}{c}\text { Biodegradation } \\
\text { constant }(d) \text { day }^{-1}\end{array}$ & Marques (2001) & Marques et al. (2003) & $\begin{array}{c}\text { Proposed constitutive } \\
\text { model }\end{array}$ \\
\hline 0.00011 & 7.63 & 8.13 & 7.93 \\
0.00022 & 8.12 & 8.54 & 8.60 \\
0.00032 & 8.28 & 8.67 & 8.85 \\
0.00041 & 8.33 & 8.71 & 8.95 \\
\hline
\end{tabular}




\section{Figures}
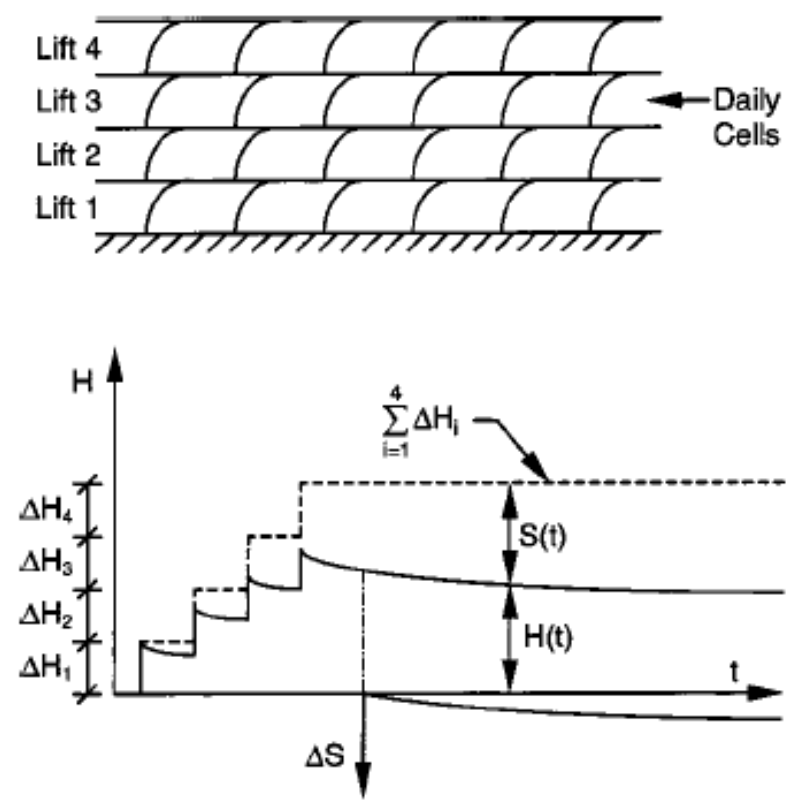

Fig.1. Waste placement process and composite model response (Marques et al. 2003)

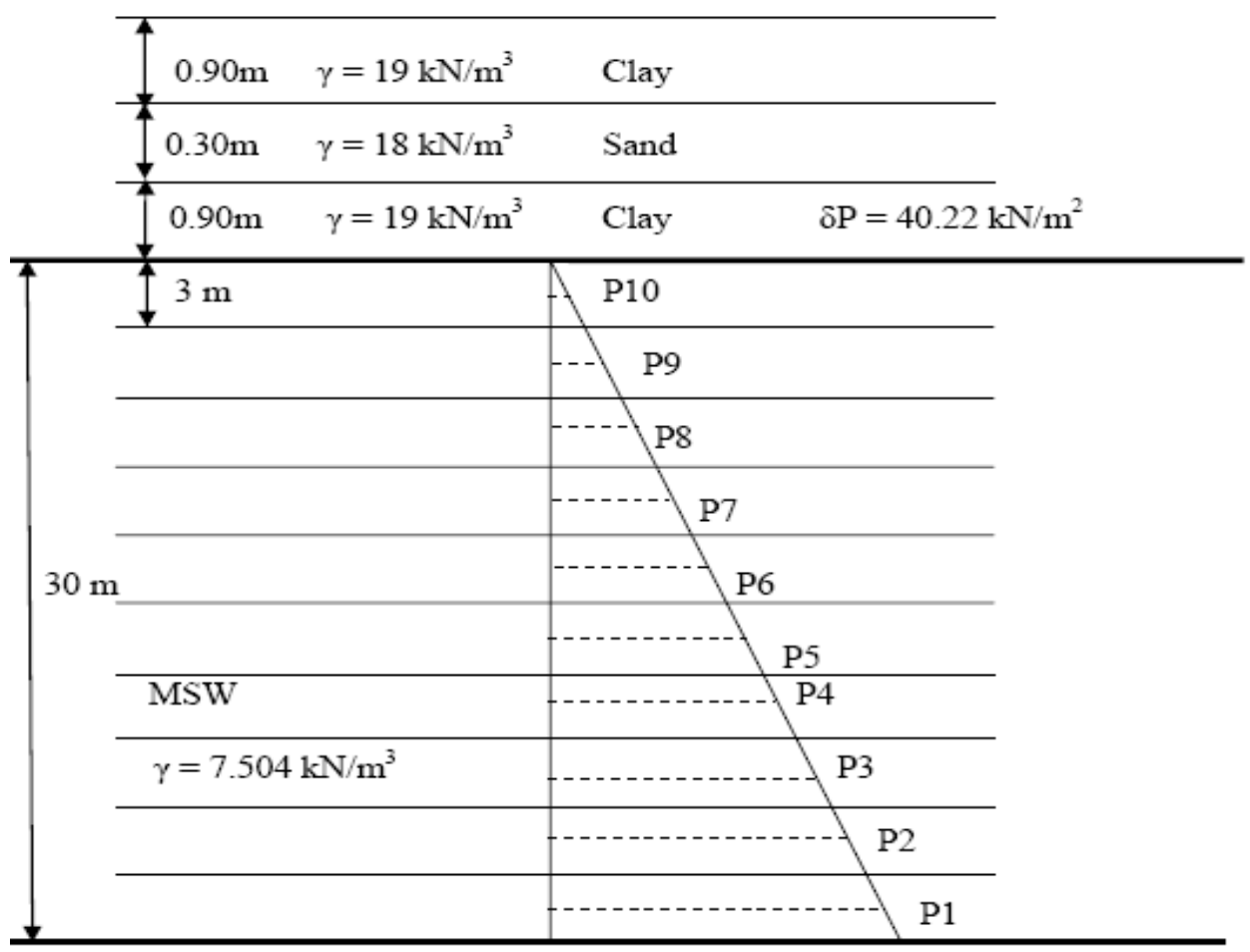

Fig. 2. MSW landfill scenario for estimation of settlement versus time 


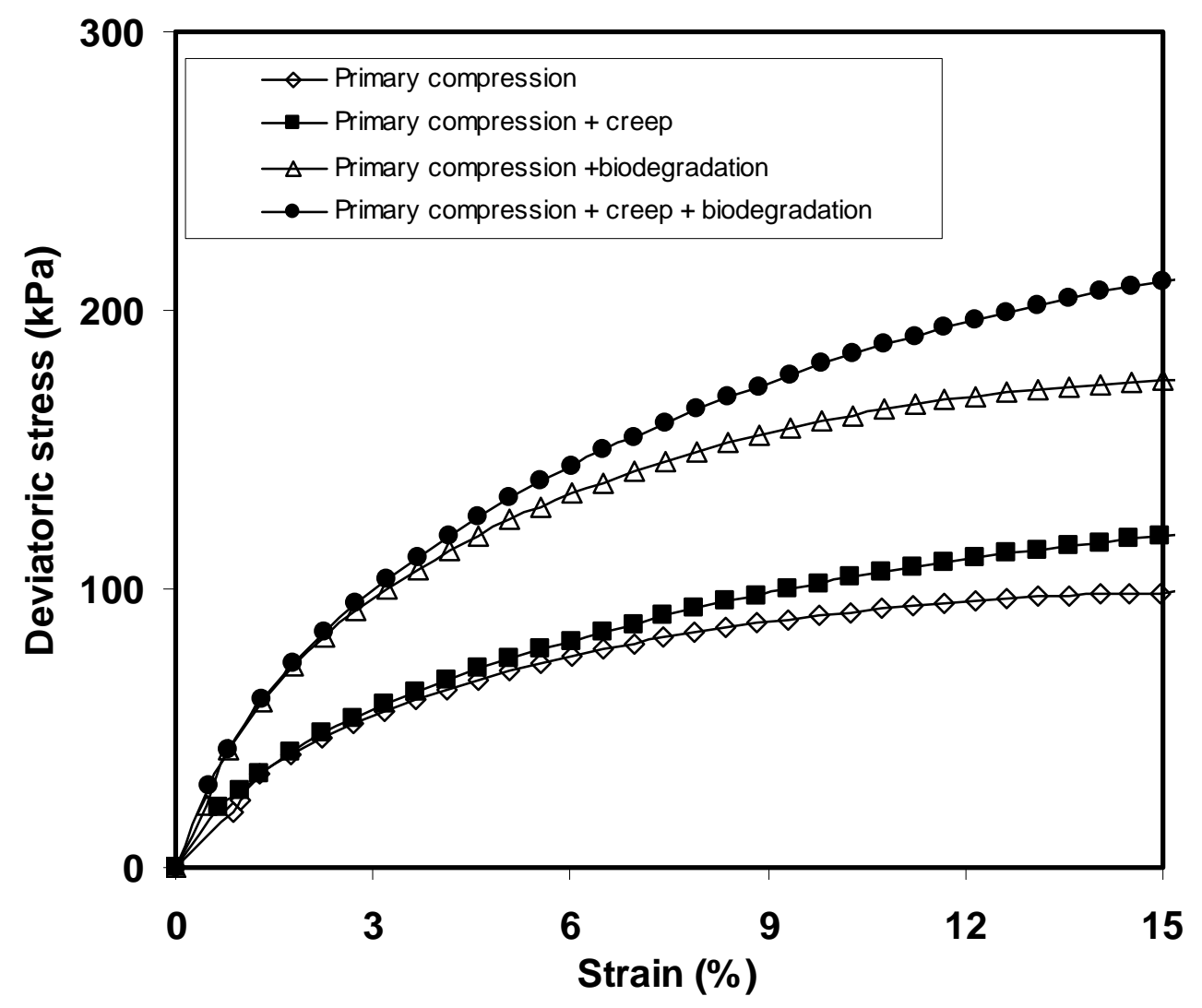

Fig.3: Stress-strain response considering different mechanism using the proposed model

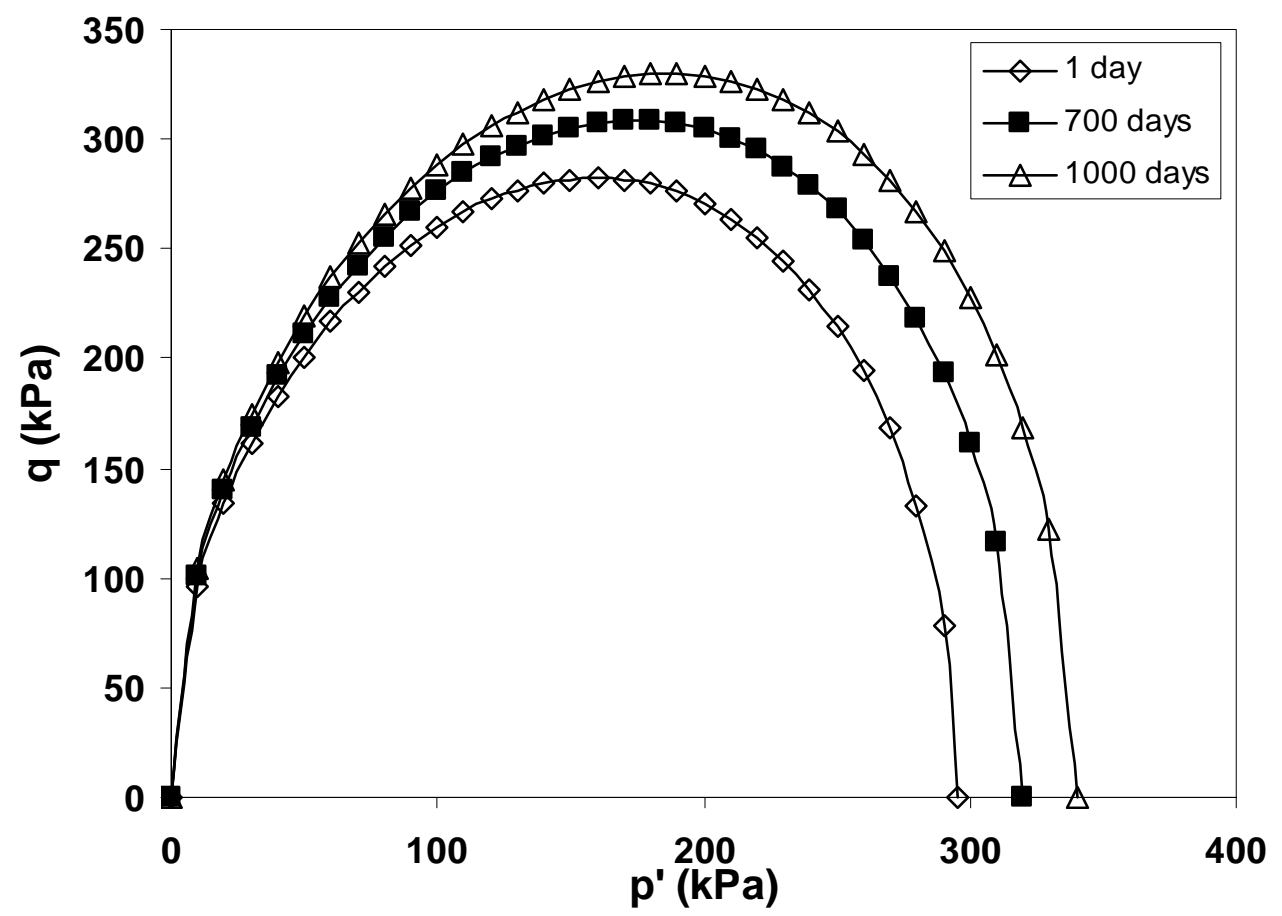

Fig.4: Yield surfaces for different times using the proposed model 


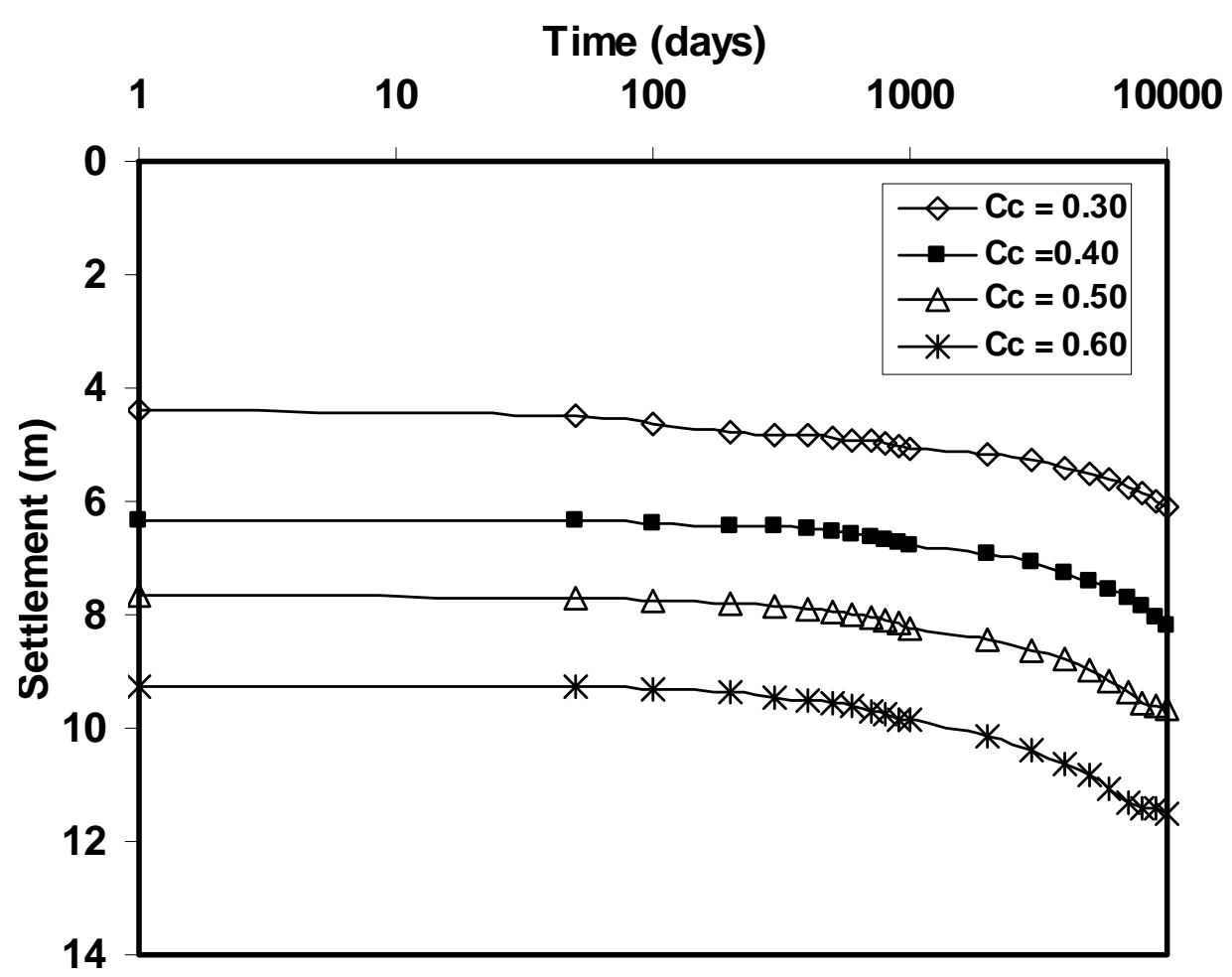

Fig 5. Time vs. settlement response of MSW for different values of compression index $\left(C_{c}\right)$ 


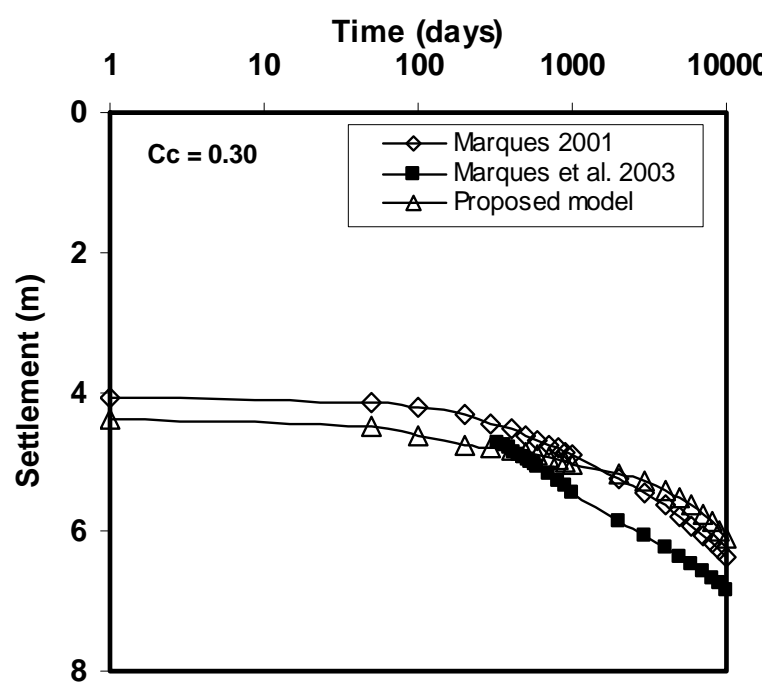

(a)

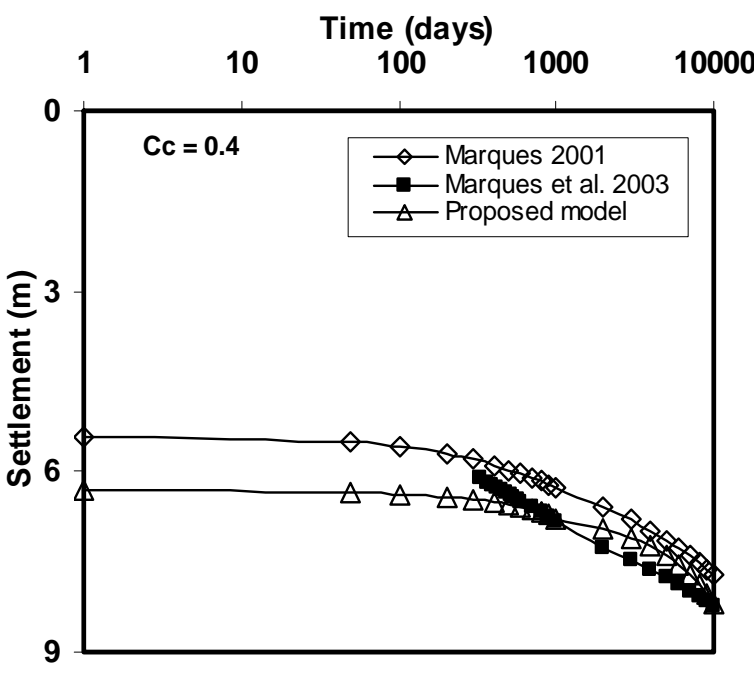

(b)

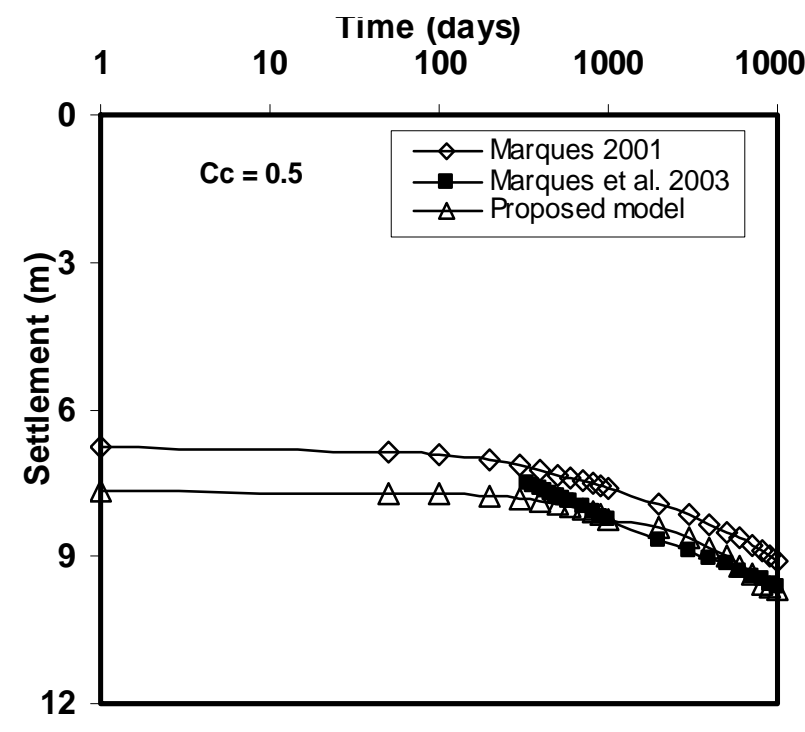

(c)

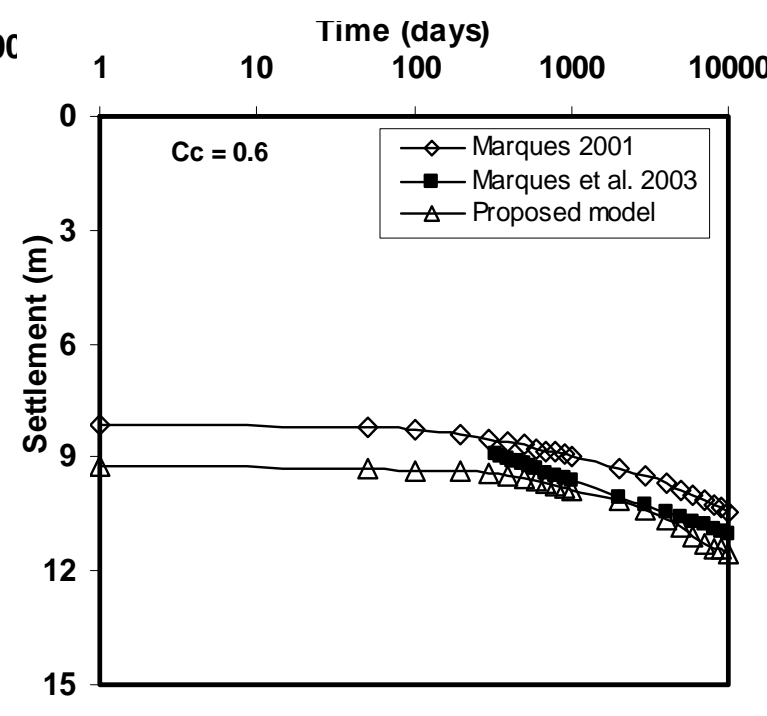

(d)

Fig 6: Influence of compression index (Cc) on time settlement response 


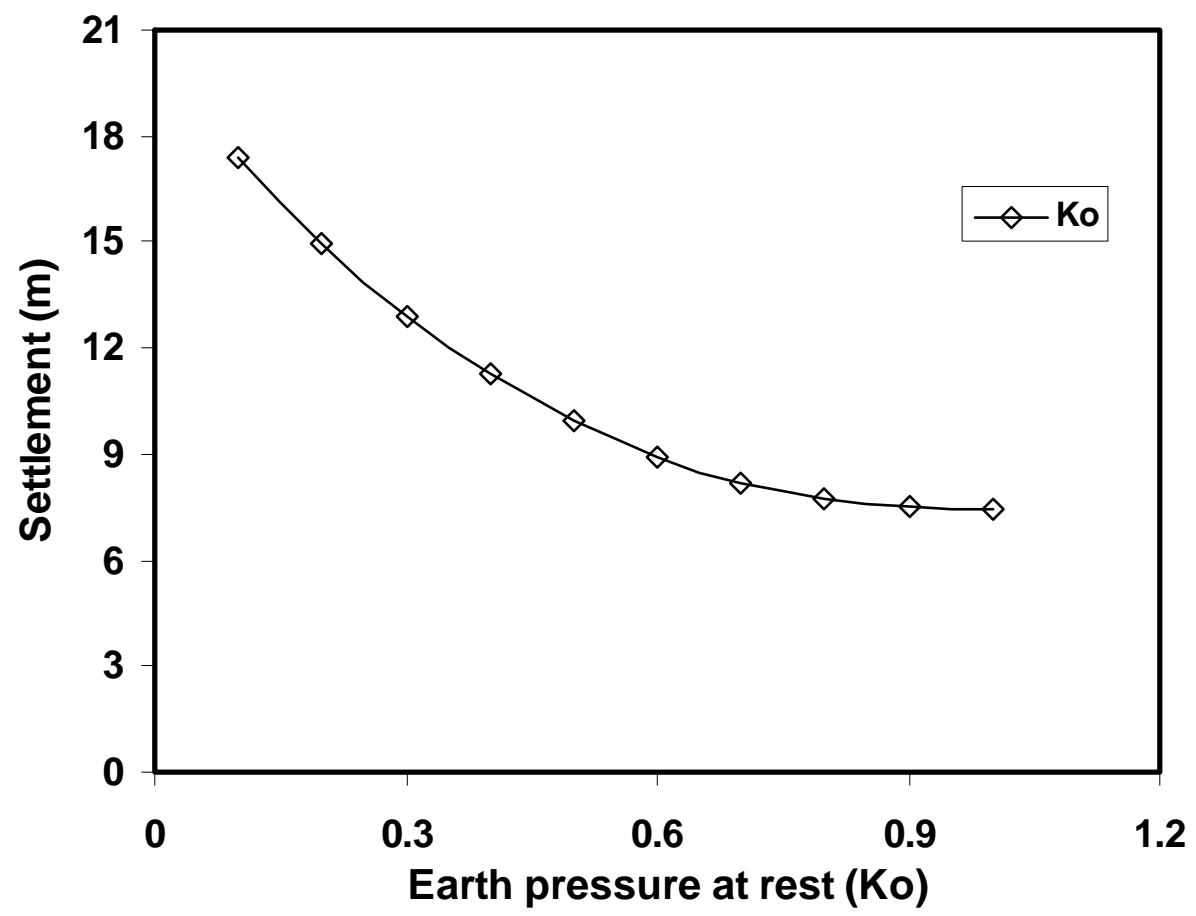

Fig. 7: Variation of earth pressure $(\mathrm{Ko})$ with settlement keeping $(\mathrm{OCR}=1)$ constant.

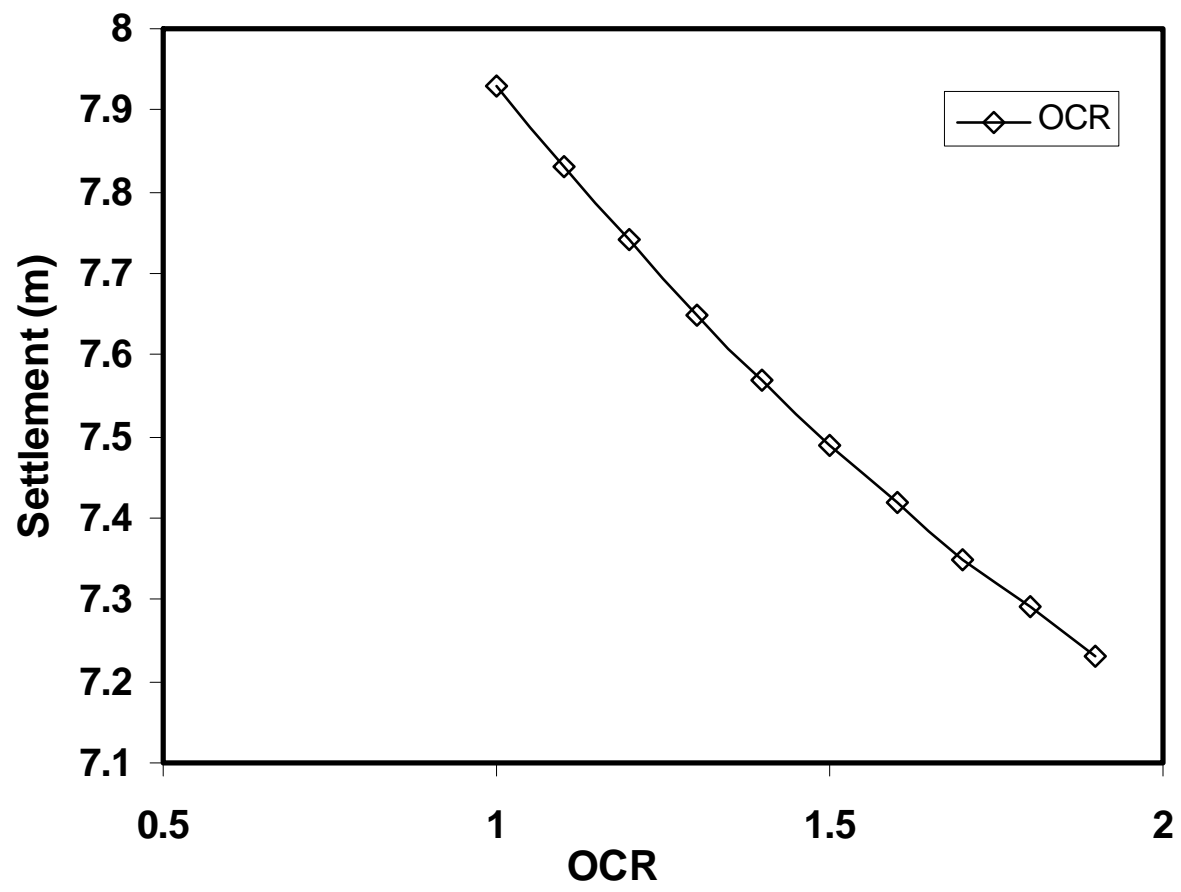

Fig. 8: Variation of OCR with settlement keeping $\left(\mathrm{K}_{\mathrm{o}}=0.6\right)$ constant. 

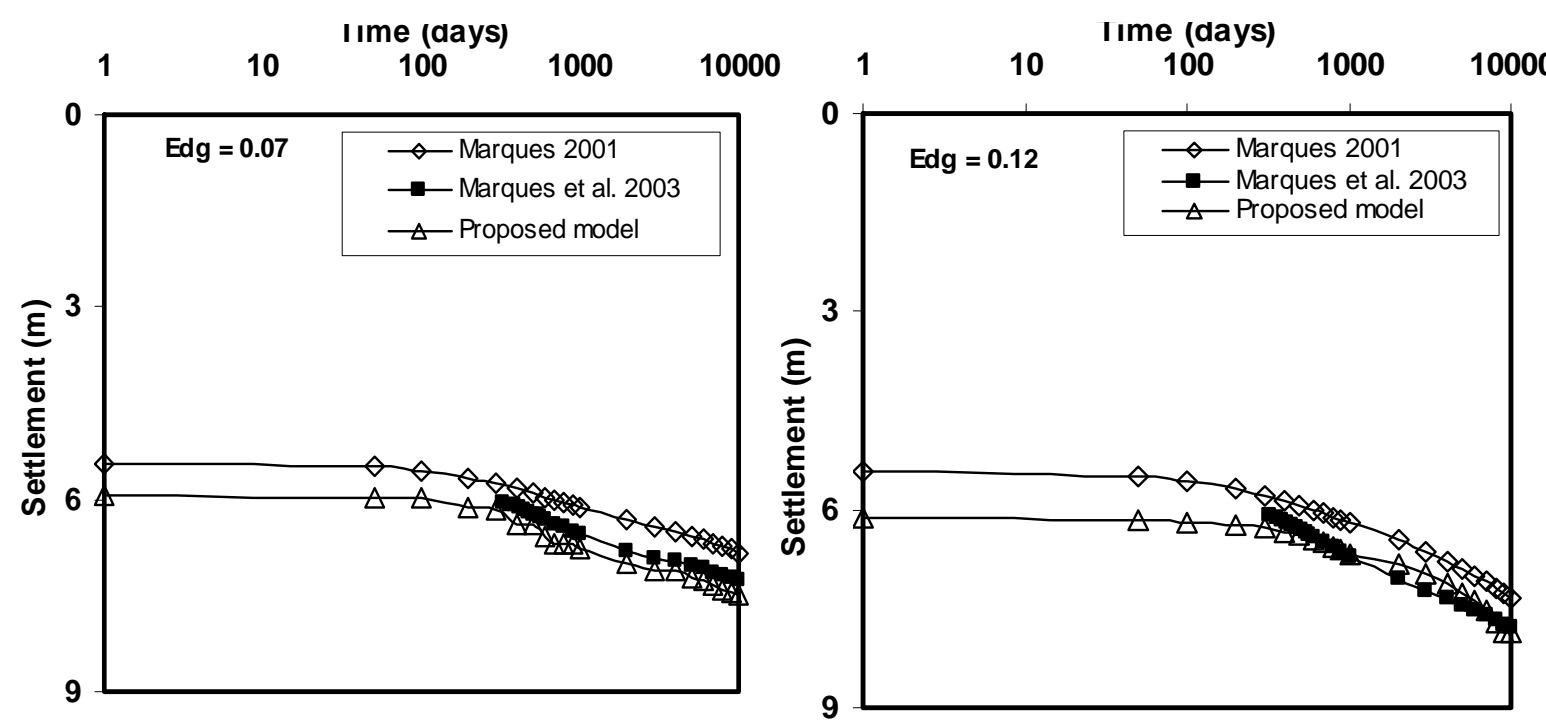

(a)

(b)

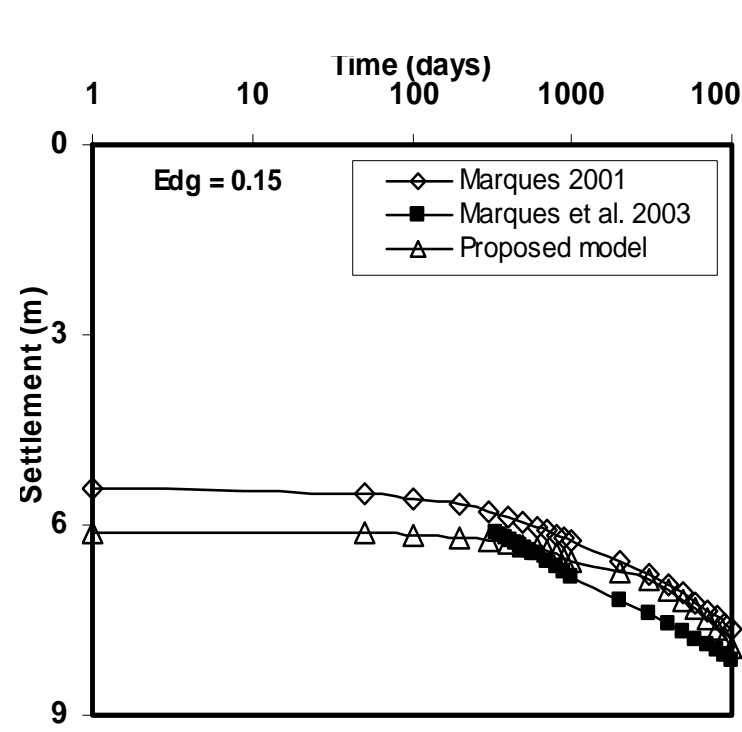

(c)

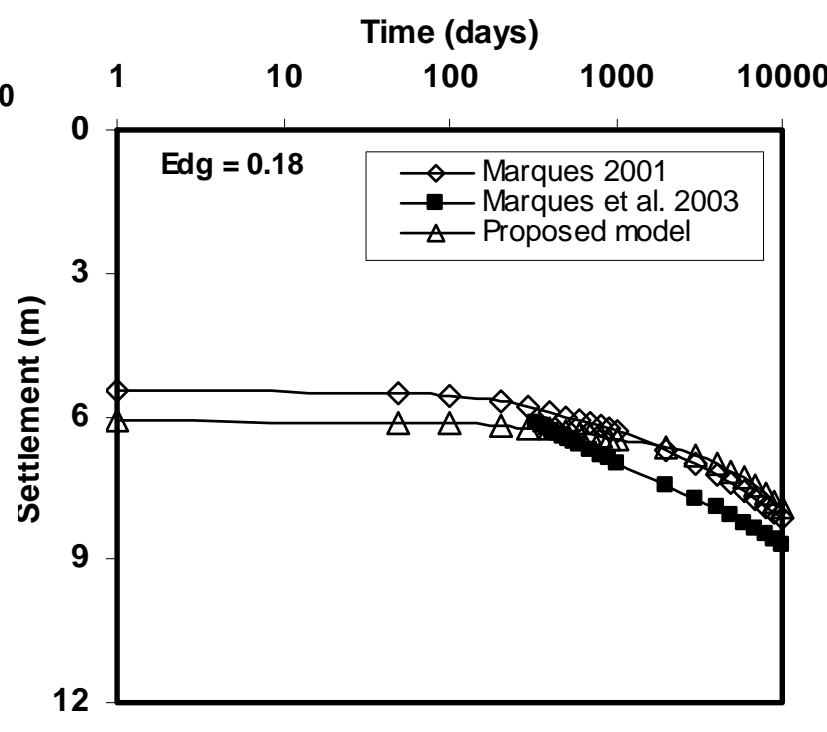

(d)

Fig. 9: Comparison of total biodegradation strain $\left(E_{d g}\right)$ with different models 


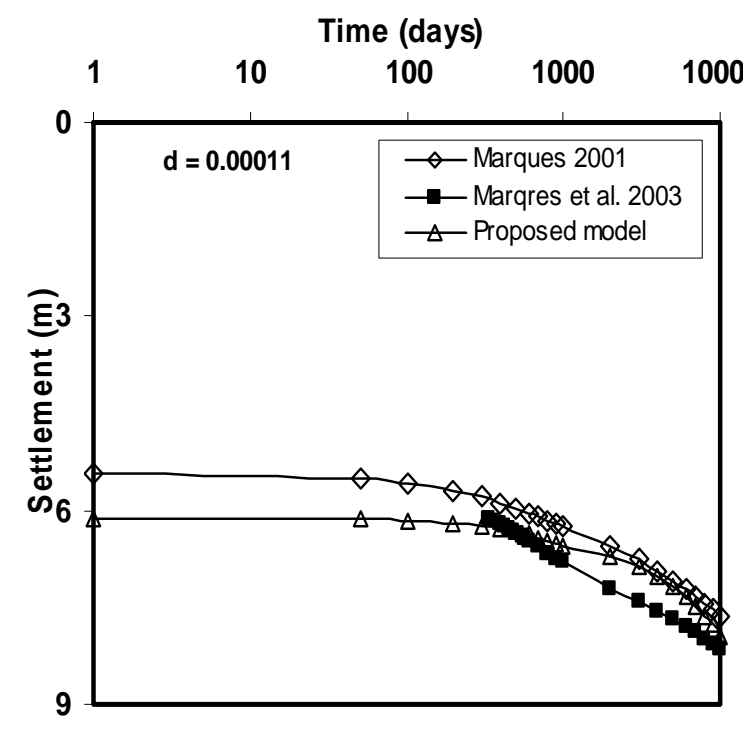

(a)

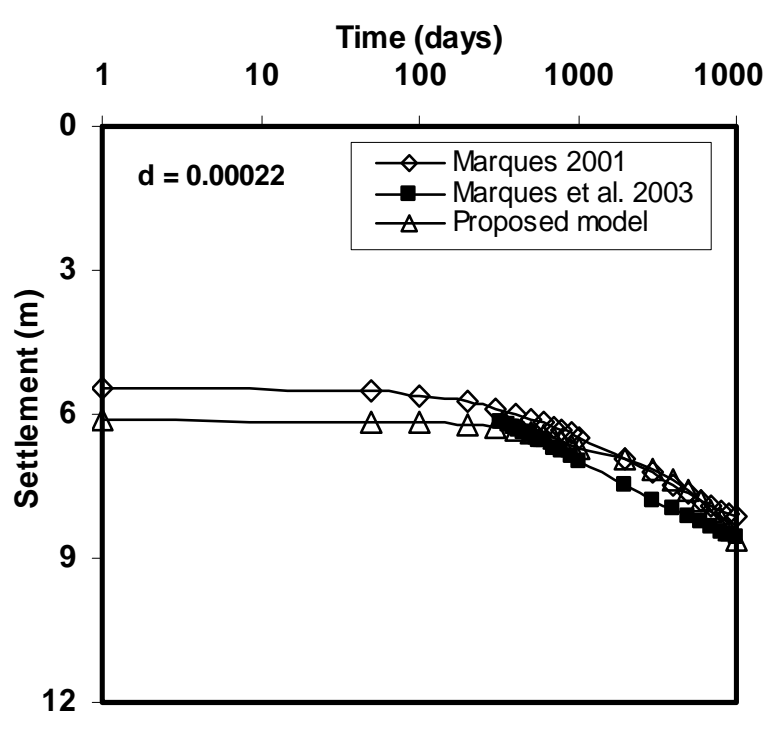

(b)

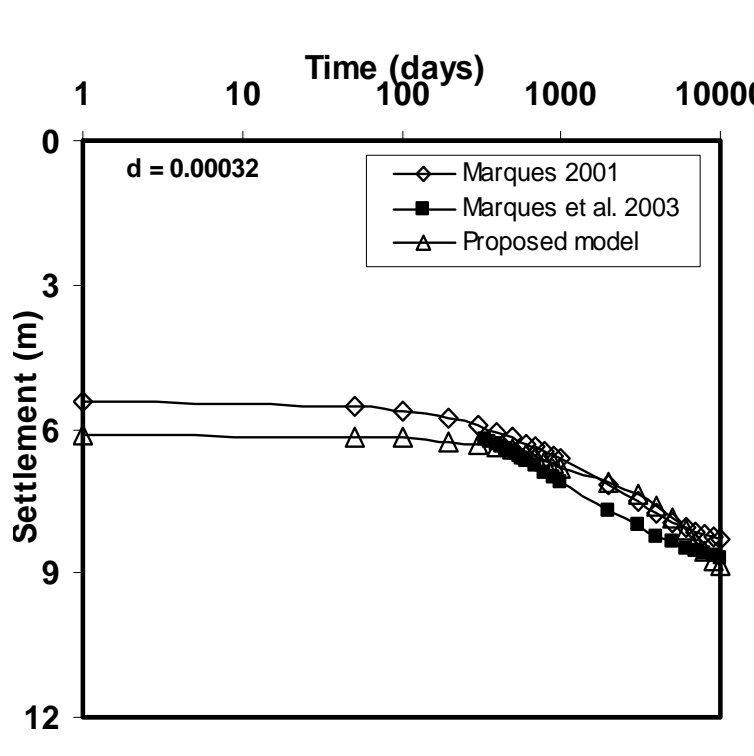

(c)

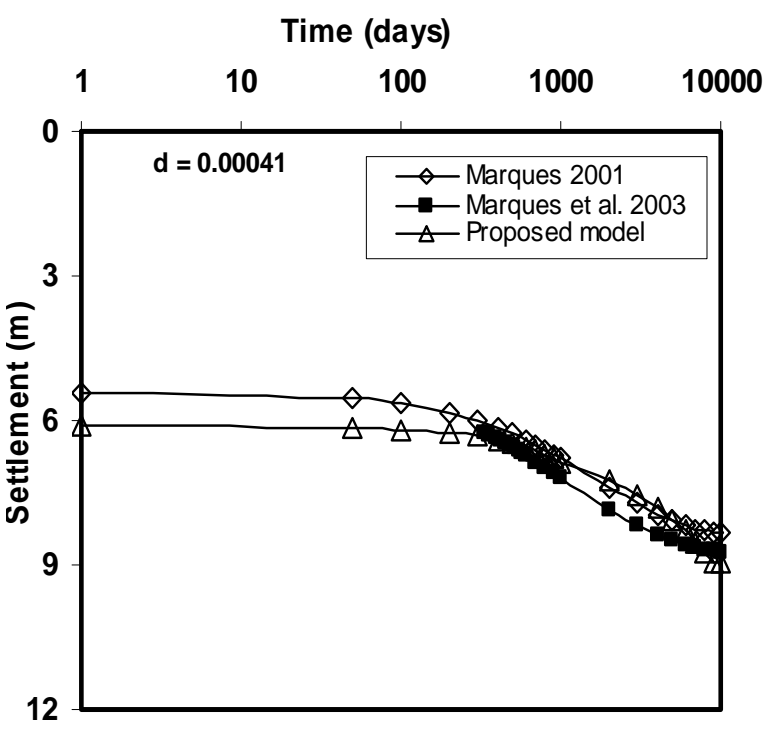

(d)

Fig 10 : Comparison of biodegradation rate constant $\left(d\right.$ in day $\left.{ }^{-1}\right)$ with different models 


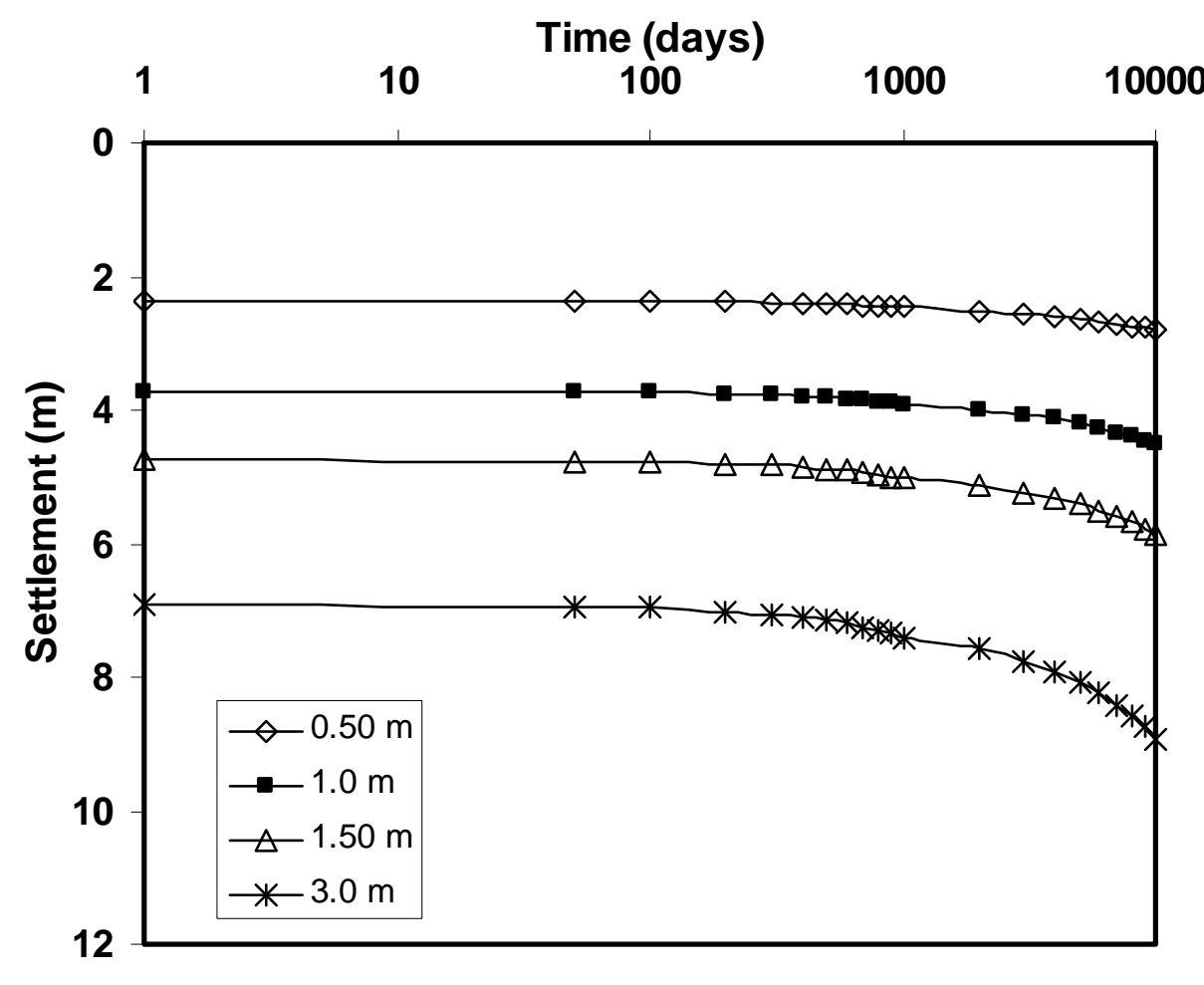

Fig. 11: Time vs. settlement for different thicknesses of waste lift 